\title{
Evaluation of the Superior Labial Musculomucosal Flap in Dogs: An Angiographic Study and Case Report
}

\author{
Cody P. Doyle ${ }^{1}$ Daniel A. Degner ${ }^{1}$ \\ ${ }^{1}$ Department of Surgery, Animal Surgical Center of Michigan, Flint, \\ Michigan, United States \\ Vet Comp Orthop Traumatol 2019;32:133-138.
}

\author{
Address for correspondence Cody P. Doyle, DVM, Department of \\ Surgery, Animal Surgical Center of Michigan, Flint, Michigan, \\ United States (e-mail: cdoylevet@gmail.com).
}

\begin{abstract}
Objective The aim of this study was to evaluate the angiosome of the superior and inferior labial arteries within the superior and inferior labia and to describe superior and inferior labial musculomucosal axial pattern flaps that can be used for intra-oral wound reconstruction. This study also presents the clinical use of a superior labial musculomucosal flap in a dog.

Materials and Methods The common carotid arteries of six canine cadavers were injected with barium sulphate. The skin of the face and labial mucosa was removed and radiographed to study the vascular supply of the superior and inferior labia.

Results The angiograms in all dogs demonstrated that the superior and inferior labial

Keywords

- oral surgery

- skin and soft tissue reconstruction

- superior labial artery

- dog

- superior musculomucosal flap arteries were located within the musculomucosal layer of the labia. At the junction of the rostral and caudal half of the upper lip, extensive choke anastomoses joined the angiosome of the infra-orbital artery. The inferior labial artery perfused the caudal half of the lower labium and had extensive choke anastomoses with the middle and rostral mental arteries. Clinical Significance The musculomucosal flaps of the superior and inferior labia contain a rich arterial blood supply, which suggests that these flaps may survive in live dogs. The superior labial musculomucosal flap was successfully used to reconstruct a large cleft palate in a single clinical case.
\end{abstract}

\section{Introduction}

Causes of palatine defects can be either congenital or acquired. Congenital palatine defects can be inherited or a sequel from intrauterine stress. ${ }^{1}$ Acquired palatine defects can be due to infection such as severe periodontal disease with tooth loss, electrical shock, trauma, chronic foreign bodies wedged upon the hard palate, surgical excision of neoplasms and radiation therapy. ${ }^{2-4}$ These acquired palatine defects are usually located off midline at the site of the injury or disease such as a oronasal fistula due to a loss of the incisive or maxillary bone from severe dental disease. Congenital hard palate defects are usually located on the midline due to abnormal embryological development.

Reconstruction of surgical conditions of the hard and soft palate can be very challenging, since palatine mucosa has limited mobility. Several choices are available for closure of wounds of the hard and soft palates. Rostral defects can be treated with transposition flaps from the labial mucosal and palatine mucoperiosteal flaps. Techniques traditionally used to reconstruct midline palatine cleft defects include the procedure of Ford which involves the use of bilateral or unilateral folding mucoperiosteal palatine flaps. ${ }^{5}$ Bilateral bipedicle palatine mucoperiosteal flaps can also be used, but tension on the closure may be associated with a greater risk of dehiscence. With both of these procedures, the exposed palatine bone from donor sites heals with migration of epithelium. A third method for repair of midline palatine defects is bilateral labial mucosal flaps with removal of the premolar and molar teeth on the left and right maxillary arcades. received

May 7, 2018

accepted after revision

December 4, 2018 (c) 2019 Georg Thieme Verlag KG Stuttgart · New York
DOI https://doi.org/ 10.1055/s-0039-1677746. ISSN 0932-0814. 
When cleft palate defects are too large to be repaired with standard techniques, additional tissue flaps are needed to successfully close the defects. Other surgical options may include the use of hair bearing skin flaps such as the cutaneous angularis oris or a cutaneous lateral cheek flap. ${ }^{6-8}$ Microvascular free tissue transfer of muscle flaps or myoperitoneal or rectus abdominis flaps have been described and provide a onestage method of intra-oral repair. ${ }^{9}$ As specialized training is required to perform this procedure, it is not commonly employed. Lastly, placement of an obturator in the palatine defect may be successful if the defect is not too large. ${ }^{10-12}$

Bryant and colleagues have described the use of a mucosal flap from the lip commissure based on the angularis oris artery. ${ }^{13}$ This flap can be created as an island flap for palatine defect reconstruction. We proposed to take this concept one step further and create a superior lip musculomucosal flap based on the superior labial artery and vein that has adequate length to reach the rostral aspect of the palate. The purpose of this study is to describe the anatomic location of the facial artery and its terminal branches supplying the musculomucosal tissues of the superior and inferior labia. We hypothesized that the angiosome of the superior labial artery will extend over the length of the superior lip to safely utilize this flap for reconstructive surgery. We also hypothesized that the vascular supply is located within the musculomucosal layer. A clinical case will also be presented to demonstrate the successful use of this flap.

\section{Materials and Methods}

Six canine cadavers were used for this study. The dogs were all euthanatized for reasons unrelated to this study. Cadavers were stored at $0^{\circ} \mathrm{C}$ until needed, then thawed to room temperature for dissection. An incision was made over the left lateral mid cervical region to allow dissection down to the left common carotid artery. The common carotid artery was transected and a 5 French red rubber catheter was placed $3 \mathrm{~cm}$ into the cranial portion of the vessel. A single metric 3.5 glycomer 631 (Covidien, Dublin, Ireland) transfixation ligature was placed around the catheterized artery $1 \mathrm{~cm}$ proximal from the cranial transected end. Using hand pressure, $15 \mathrm{~mL}$ barium sulphate (Liquibar, 60\% [w/w] barium sulphate; E-Z-EM Inc., Westbury, New York, United States) was injected into the common carotid artery. The injection of barium was similarly performed in the right common carotid artery. Pilot studies revealed that $15 \mathrm{~mL}$ of barium sulphate was sufficient to properly fill the injected common carotid artery and all of its terminal arterial branches to the facial region.

The skin of the face and the labial mucosa were removed via sharp dissection. Care was taken to preserve the mucosa, underlying labial muscles and skin of the superior and inferior labia. The masseter muscle was collected with the excised skin to preserve the trunk of the facial artery. The limits of the dissection were as follows: nasal planum rostrally, level of the pinna caudally, ventral and dorsal midline of the head. The left and right excised facial skin flaps were radiographed with a high definition digital radio-

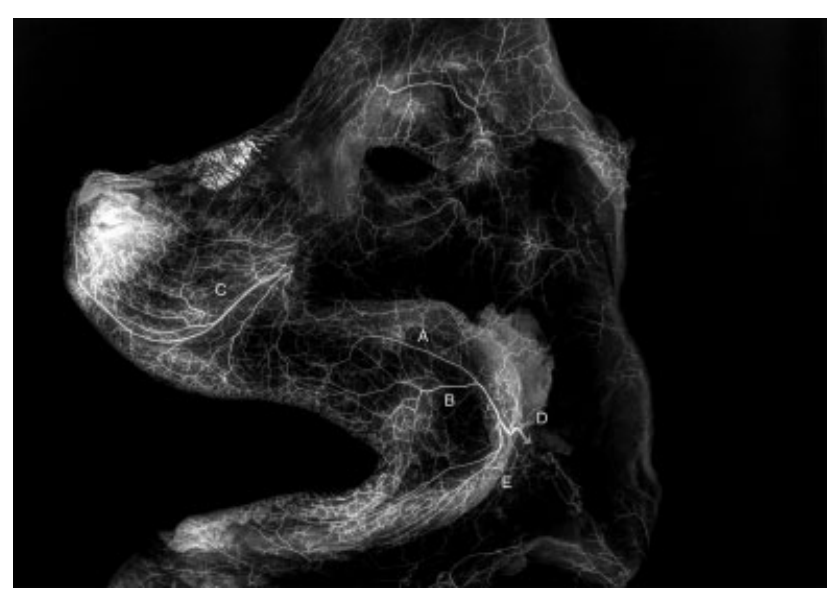

Fig. 1 Angiogram of the entire face before the superior and inferior musculomucosal portions of the labia removed. Take note of the superior and inferior labial arteries. Extensive choke anastomoses are seen between the superior labial artery and infraorbital artery. Legend: $\mathbf{A}=$ superior labial artery, $\mathbf{B}=$ angularis oris artery, $\mathbf{C}=$ infraorbital artery, $\mathbf{D}=$ facial artery, $\mathbf{E}=$ inferior labial artery.

graph machine (Cuattro DR, Heska, Loveland, Colorado, United States). The radiographs were studied to determine the location of the facial artery and its terminal branches (-Fig. 1). The entire labial mucosa with underlying orbicularis oris muscle was then removed from the facial skin. This mucosal flap with attached orbicular oris muscle was then radiographed (-Fig. 2). Finally, the remaining facial skin was also re-radiographed. The three sets of radiographs for each cadaver were used to study the angiosomes.

\section{Results}

In all six cadavers, the angiographic pattern of the facial artery and its tributaries was consistent in both the left and right sides. The facial artery extended along the ventrolateral aspect of the masseter muscle and rose dorsally to split into the superior and inferior labial arteries. The angularis oris extended into the tissues of the commissure of the lips. The

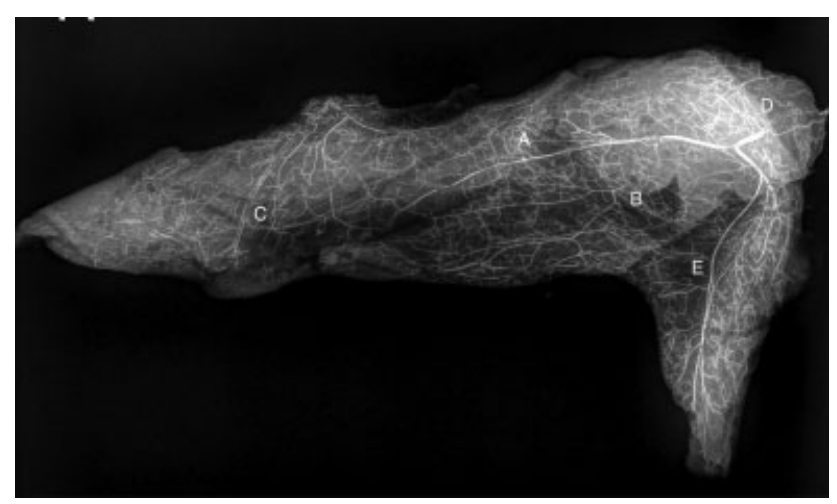

Fig. 2 Following removal of the skin from the superior and inferior labia, the angularis oris, superior labial and inferior labial arteries are seen to remain with the musculomucosal portion of the labia. Legend: A = superior labial artery, $\mathbf{B}=$ angularis oris artery, $\mathbf{C}=$ infraorbital artery, $\mathbf{D}=$ facial artery, $\mathbf{E}=$ inferior labial artery. 
primary angiosome of the superior labial artery was located in the caudal half of the upper lip. At the junction of the rostral and caudal half of the upper lip, extensive choke anastomoses joined the angiosome of the infra-orbital artery. The angiosome of the infra-orbital artery was located in the rostral half of the upper lip. From the radiographic studies, the superior labial artery was intimately associated with the mucosa and orbicularis oris and a fine network of vessels seen in the final radiographs made from the facial region with the mucosa and orbicularis oris excised. Based on gross observations, the superior labial vein extended the full length of the superior lip.

The angiosome of the inferior labial artery extended approximately $60 \%$ of the lower lip with extensive choke anastomoses from the caudal and middle mental arteries. Similar to the upper lip, the inferior labial artery was located in the mucosa and orbicularis oris muscle. The inferior labial vein likewise extended the length of the flap.

Radiographs made of the skin after the musculomucosal flap was removed revealed the skin was void of the facial artery and its terminal branches proving the arteries were entirely suspended in the mucosa and associated muscles of the superior and inferior labia. This was consistent in all cadavers.

\section{Clinical Case Report}

A 2-year-old, neutered male Pitbull dog was presented for the complaint of persistent nasal discharge and rhinitis due to a secondary cleft palate. Examination revealed a large midline defect of the hard and soft palate with foreign material lodged into the nasal cavity ( $\mathbf{- F i g . ~} \mathbf{3}$ ). Due to the extensive size of the defect in the hard palate, there were concerns that traditional hinge flaps may not be adequate to close the defect.

During the reconstruction of the hard palate, an incision was made adjacent to the left and right dental arcades to create bilateral mucoperiosteal hinge flaps. The palatine mucoperiosteum was dissected from the palatine bone with a Freer periosteal elevator to the level of the edge of

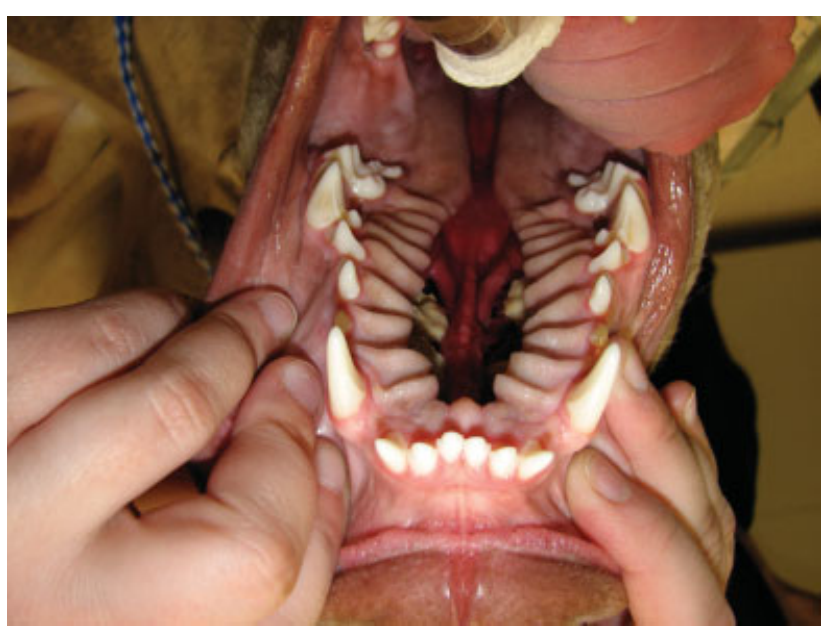

Fig. 3 Open mouth view of the palate. A very large cleft palate is evident in this mature Pitbull dog.

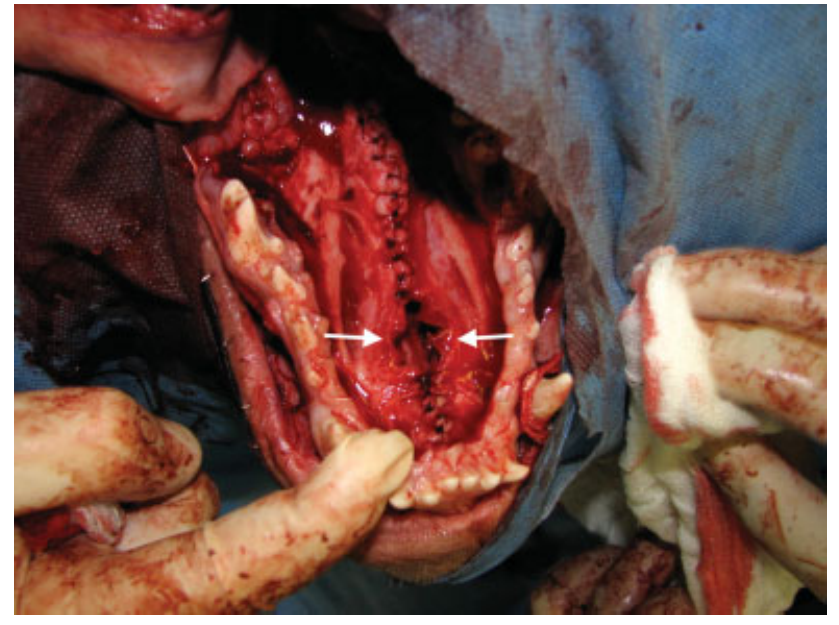

Fig. 4 Open mouth view of the palate. Bilateral hinge mucoperiosteal flaps were created from the residual hard palate and sutured on mid line. Take note of the residual rostral hard palatine defect (arrows).

the palatine defect. The left and right periosteal flaps were folded over in a hinge fashion and apposed along the midline of the palatine defect with metric 3 polydioxanone (Ethicon, Somerville, New Jersey, United States) in a simple interrupted pattern. A remaining defect in the rostral third of the hard palatine region with dimensions of $3 \mathrm{~cm}$ by $1 \mathrm{~cm}$ could not be closed.

The soft palate was reconstructed using overlapping mucosal flap technique (-Fig. 4). During this repair, an incision along the lateral aspect of the left residual soft palate and a mucosal flap with palatal muscle was developed with a hinge along the medial border of the left palatal tissue. An incision was made on the dorsal aspect of the residual right soft palate mucosa, at the lateral edge and a flap was created with the hinge at the medial border and a second mucosal flap was created. The left soft palatal flap was sutured to the cut mucosal surface on the right nasopharynx and the right palatal flap was overlapped and sutured to the incised mucosa on the dorsal palate.

To reconstruct the remaining rostral hard palatine defect, a superior labial musculomucosal flap was developed. The lip was transilluminated with an operating lamp from the skin side to visualize the vascular supply to the superior lip (-Fig. 5). The borders of the peninsular flap were then drawn on the lip mucosa with a surgical marking pen, incorporating the vascular supply within the flap design (-Fig. 6). The musculomucosal flap extended rostrally to the level of the canine tooth, $10 \mathrm{~mm}$ from the mucocutaneous junction ventrally and within $5 \mathrm{~mm}$ from the fixed gingival margin. The base of the flap was at the level of the second upper left molar tooth. After incising the mucosa, a plane of dissection was established between the skin and the orbicularis oris muscle. The left upper molars $(209,210)$ were removed and the alveolar bone was removed with a pneumatic bur to create a slight concavity in the caudal maxillary region to prevent compression of the base of the flap when the mouth was closed. The flap was then passed through the bridging channel and placed over the hard palate ( - Supplementary Fig. 1, 


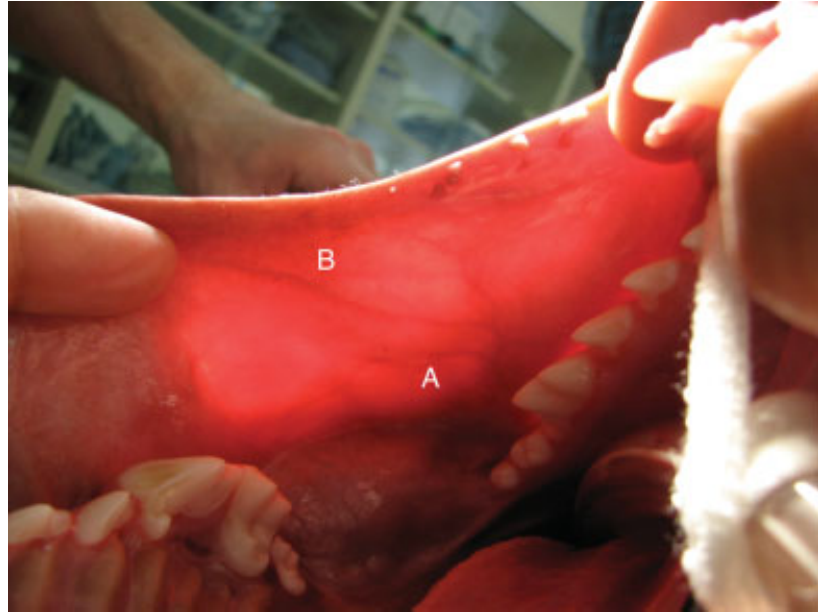

Fig. 5 View of the transilluminated commissure and superior lip from the oral aspect of the lip. Take note of the angularis oris artery (A) and superior labial artery (B).

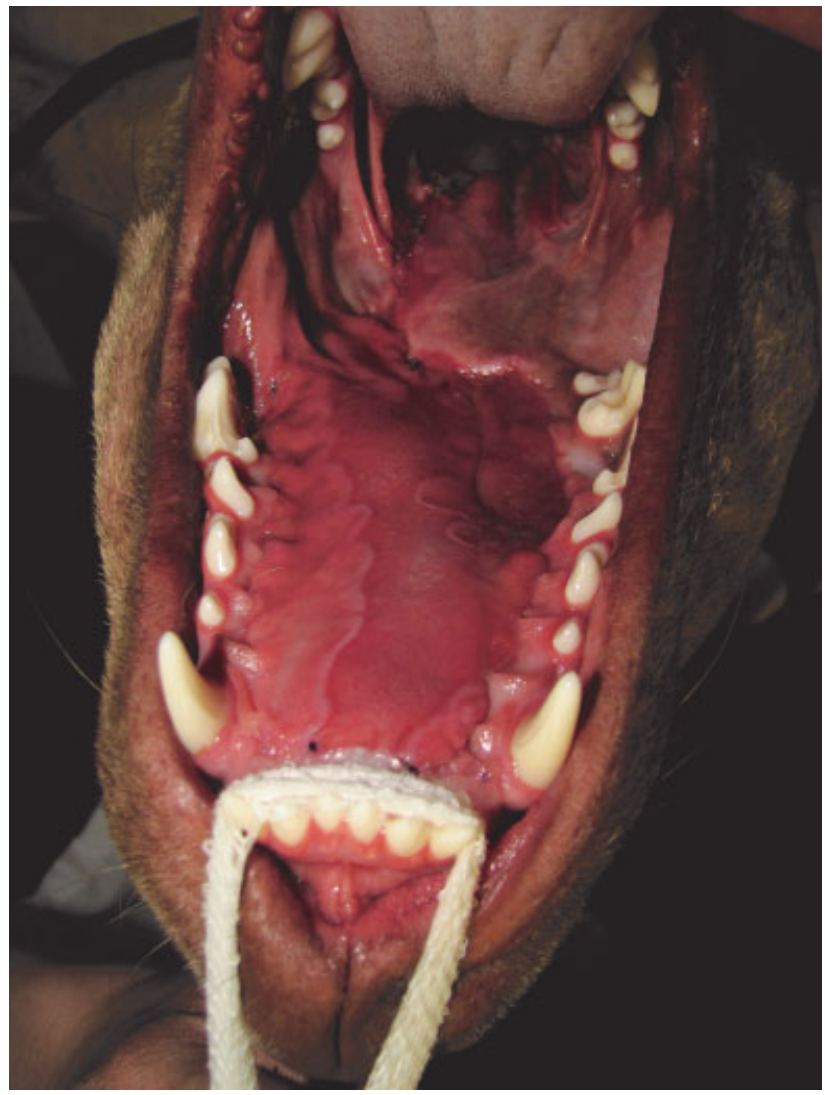

Fig. 7 Open mouth view of the hard palate 3 weeks after surgery. Take note that no residual palatine defect is present. Epithelium has migrated across a portion of the hard palate.

available in the online version only). The flap was sutured to the rostral and left side of the palatine mucoperiosteal incision along the dental arcade with metric 3 polydioxanone in a continuous pattern ( - Fig. 7). The flap was also sutured to the residual edges of the soft palatine flaps. Due to flap width limitations, the mucosal portion of the flap could not be

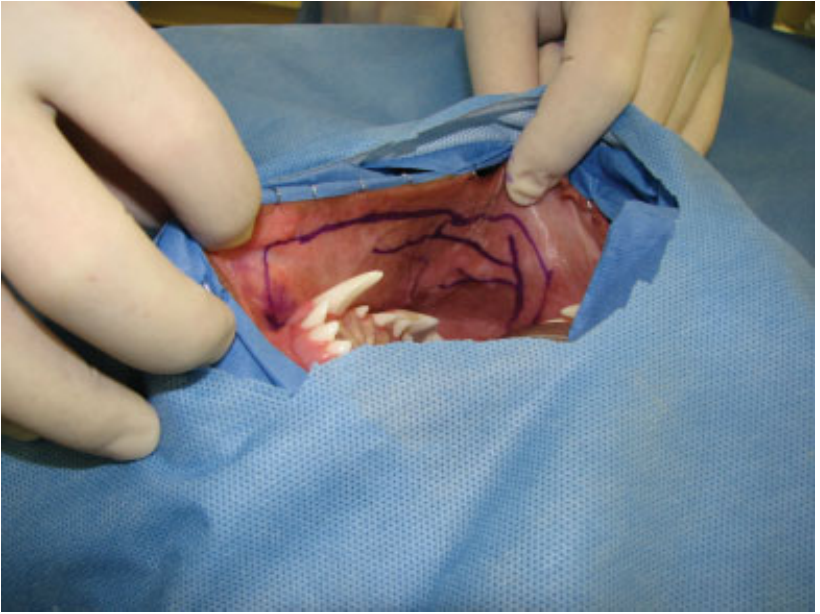

Fig. 6 View of the superior lip from an oral view. The outline of the proposed musculomucosal superior labial flap is drawn on the mucosa along with the location of the blood supply, as depicted from transillumination of the lip.

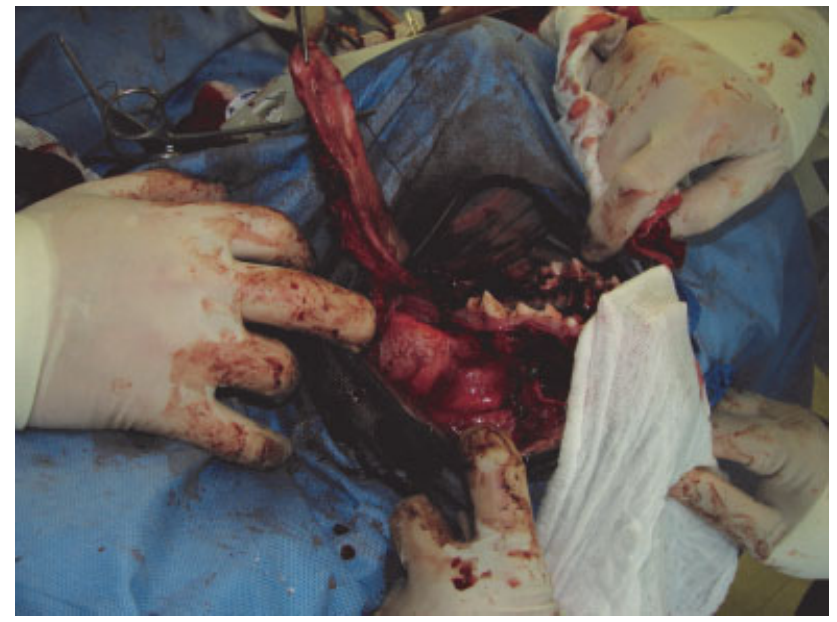

Fig. 8 View of the superior lip from a lateral view. The superior labial musculomucosal flap has been elevated and left as a pedicle flap at the level of the caudal commissure.

sutured to the right mucoperiosteal incision; however, available orbicularis oris muscle attached to the flap was sutured to the left side. The donor site was closed with metric 3 polydioxanone in a continuous pattern. Re-examination of the oral cavity at 3 and 8 weeks did not reveal any signs of necrosis of the musculomucosal flap and no oronasal fistulas were found. Migration of mucosa was noted over the hard palate and was complete at 8 weeks after surgery ( $\mathbf{- F i g . ~ 8 ) . ~ M o d e r a t e ~ d o r s a l ~}$ upper lip deviation was noted, but this did not impede function of the oral cavity in this patient (-Supplementary Fig. 2 , available in the online version only).

\section{Discussion}

In 1992, the facial artery musculomucosal axial pattern flap was described to treat oronasal fistulas in human patients. This flap is used to treat anterior defects of the hard palate that 
previously were difficult to repair by traditional repair methods. ${ }^{14}$ In veterinary medicine, Bryant and colleagues were the first to describe a musculomucosal axial pattern flap based on the angularis oris artery to cover recurrent palatal defects in three clinical cases. Their flap was primarily based on mucosa located in the commissure and caudal lip which limited reconstruction to palatine defects that extend rostrally to the level of the third upper premolar tooth. ${ }^{13}$ The superior labial flap described in our study has a greater length, thus can be used for more rostrally located palatine defects.

In dogs, the facial artery is a terminal branch of the external carotid artery and is approximately $3 \mathrm{~cm}$ long and $1.5 \mathrm{~mm}$ in diameter. It arises at the angle of the mandible $1 \mathrm{~cm}$ from the lingual artery and gives rise to multiple terminal branches. The facial artery is surrounded by the masseter muscle dorsally and laterally, the digastricus muscle ventrally and the styloglossal muscle medially. ${ }^{715}$ The facial artery terminates in the face as multiple labial arteries. The facial artery bifurcates into the inferior labial artery and superior labial artery. The angularis oris artery branches ventrally from the superior labial artery and courses rostrally and ventrally. The superior labial artery anastomosis with the terminal branches of the infraorbital artery, the lateral nasal artery and rostral septal branches of the infraorbital artery.

This study demonstrated that the superior labial artery and angularis oris artery supply the caudal half of the superior labia, and the infraorbital artery supplies the rostral half of the superior labia in the canine cadavers. Extensive choke anastomoses exist between the angiosome of the superior labial artery and the infraorbital artery, which will provide good arterial perfusion to the upper lip. Typically, axial pattern flaps will have good survival when based on the primary and secondary angiosome. Of equal or greater importance is venous drainage of a flap. Axial pattern flaps that are based on a dominant vein in humans have been shown to have excellent survival, without having a robust dominant arterial blood supply. ${ }^{14}$ The superior labial vein travels the full length of the lip to join the inferior labial vein, which continues as the facial vein. This is critical for survival of the superior labial flap. This study also evaluated the depth of the vascular supply (skin versus muscle/mucosa). Based on the second part of the study, in which the musculomucosal flaps were radiographed, the arterial vascular supply was found to be within these layers, rather than primarily in the hypodermis of the skin. This suggests that the vascular supply associated with the skin is not significant and the musculomucosal flap should have robust perfusion.

Based on the findings of our study, it is likely that a musculomucosal flap of the entire upper lip and commissure would survive in clinical patients. However, from a practical view, this flap only needs to extend rostrally to the upper canine tooth for a clinical case having a defect that extends to the rostral hard palate. A small margin of $\sim 1 \mathrm{~cm}$ of mucosa on the ventral (mucocutaneous junction) border of the superior lip should be left attached to the lip to help with cosmesis of the donor site postoperatively. The dorsal border of the flap can be a few millimetres from the junction of the fixed gingival, to provide adequate mucosa for suturing.
To prevent compromising the blood supply of the flap, it should not be rotated more than 180 degrees, it should not be compressed when the mouth is closed and tension should not be placed on the flap once it is sutured in place. The arc of rotation of the flap is minimal as it needs to be twisted approximately 90 degrees along its long axis. The arc of rotation is quite minimal, as the primary use of the flap would be to reconstruct rostral palatine defects. Very caudal soft palatine defects also can be reconstructed with this flap and again the arc of rotation would not exceed 180 degrees. Minimizing tension on the flap is achieved by ensuring an adequate length of the flap. Minimizing compression of the vascular supply of this flap can be achieved by removing the last two molar teeth and creating an osseous furrow in the maxillary bone with a pneumatic bur. This has also been the technique that we have used when passing the vascular leash of microvascular free muscle flaps across the dental arcade from a lateral to medial direction for reconstruction of palatine defects in dogs. ${ }^{9,16}$

Due to the robust blood supply of the superior labial musculomucosal flap, based on a single artery and vein, it could be created either as an island or peninsular flap. Because the arc of rotation of this flap is not very large when using it to reconstruct rostral palatine defects, this flap does not need to be skeletonized about its pedicle. Generally, the primary reason to create the flap as an island flap is to avoid 'dog ears' at the base of the flap. This was not a problem in our clinical case due to the limited arc of rotation. In addition, the use of transillumination of the lip and identification of the vascular supply will help to prevent inadvertent transection of important vessels feeding the flap. Creating flaps as island flaps may increase the risk of inadvertent transection of the vascular supply. For these reasons, our general recommendation is to create this flap as a peninsular flap.

The case presented here demonstrated that a rostral defect of the cleft palate can be successfully reconstructed using the superior labial musculomucosal flap. The mucosal portion of the flap was not wide enough to cover the entire width of the hard palate. However, the muscular portion of the flap which extended beyond the mucosal portion of the flap increased the width of the flap, thus allowing the muscle to be sutured to the right side of the palate, while the mucosal portion of the flap being sutured to the left side. A small area of exposed palatine bone could not be resurfaced with this flap. Complete survival of the flap was seen and complete epithelialization of all nonepithelial covered surfaces occurred over a period of 2 months after surgery, resulting in successful reconstruction of the large palatine defect.

One limitation of this study was that selective catheterization of the facial artery was not completed. Selective catheterization of the facial artery just prior to bifurcating into the superior and inferior labial arteries likely would have filled the infraorbital angiosome, as this study demonstrated extensive choke anastomoses between these two angiosomes.

Another limitation of this study was that this was an anatomic study, rather than a physiological one. Barium studies have been widely used previously to study the anatomical perfusion of arteries of skin and muscle flaps with similar limitations. ${ }^{7,17-19}$ Non-diluted barium sulphate 
was chosen in this study over less viscous contrast agents for several reasons. Non-diluted barium sulphate filled the common carotid and its terminal branches adequately on our pilot studies. Barium sulphate allowed us to visualize the arteries within the mucosa on visual examination and on radiographs revealed great contrast. Barium sulphate may be too thick to perfuse all of the very small terminal arteriole branches; however, in this study the flap was adequately perfused with barium throughout the flap.

Due to the anatomical location of the flap described, some possible complications may arise in the postoperative period. Since the superior labial muscle was removed from the superior labia, the lip will not move normally; however, this should be not impede normal oral function. In addition to a loss of motor function, the sensory function to the superior labial skin will be damaged and the lip may have diminished sensory input. This lack of sensation may lead to accidental selfmutilation such as biting the lip. Another concern is iatrogenic damage to the zygomatic ducts and the parotid duct. Care should be taken to create the flap just ventral to this region. If the ducts are accidently transected, a parotid or zygomatic sialocele may develop. This complication can be resolved by a parotid or zygomatic sialectomy or duct ligation.

In conclusion, this study allowed us to identify where the arteries are located in the superior labia; however, clinical cases are needed to help determine the exact survival length of the axial pattern flap. Our clinical case described allowed us to conclude that the flap may survive to the level of the canine tooth in dogs. In addition, based on the angiographic study, an inferior labial flap can also be developed if the superior labium is not available as a donor flap site; however, the width of the inferior labial flap would be narrower, but it is likely that it could be just as long as the superior labial flap.

\section{Author Contribution}

Both authors contributed to conception of study, study design, acquisition of data and data analysis and interpretation. Both authors also drafted, revised and approved the submitted manuscript.

\section{Conflict of Interest}

No conflicts of interest are present at this time with any of the authors.

\section{Funding}

The Animal Surgical Center of Michigan provided funding for this research project.

\section{Acknowledgments}

The authors would like to acknowledge the staff of the Animal Surgical Center of Michigan for donating their time for this project with special attention to Drs. Jennifer Wan and Courtney Andries.

\section{References}

1 Harvey CE. Palate defects in dogs and cats. Compend Contin Educ Pract Vet 1987;9:404

2 Beck JA, Strizek AA. Full-thickness resection of the hard palate for treatment of osteosarcoma in a dog. Aust Vet J 1999;77(03): 163-165

3 Bojrab MJ, Tholen MA, Constantinescu MG. Oronasal fistulae in dogs and cats. Compend Contin Educ Pract Vet 1986;8:815

4 Tholen MA, Johnson J. Surgical repair of the oronasal fistula. Vet Med Small Anim Clin 1983;78:1733

5 Howard DR, Davis DG, Merkley DF, Krahwinkel DJ, Schirmer RG, Brinker WO. Mucoperiosteal flap technique for cleft palate repair in dogs. J Am Vet Med Assoc 1974;165(04):352-354

6 Dundas JM, Fowler JD, Shmon CL, Clapson JB. Modification of the superficial cervical axial pattern skin flap for oral reconstruction. Vet Surg 2005;34(03):206-213

7 Yates G, Landon B, Edwards G. Investigation and clinical application of a novel axial pattern flap for nasal and facial reconstruction in the dog. Aust Vet J 2007;85(03):113-118

8 Losinski SL, Stanley BJ, Schallberger SP, Nelson LL, Towle Millard HA. Versatility of the angularis oris axial pattern flap for facial reconstruction. Vet Surg 2015;44(08):930-938

9 Degner DA, Lanz OI, Walshaw R. Myoperitoneal microvascular free flaps in dogs: an anatomical study and a clinical case report. Vet Surg 1996;25(06):463-470

10 Smith MM, Rockhill AD. Prosthodontic appliance for repair of an oronasal fistula in a cat. J Am Vet Med Assoc 1996;208(09): 1410-1412

11 Coles BH, Underwood LC. Repair of the traumatic oronasal fistula in the cat with a prosthetic acrylic implant. Vet Rec 1988;122(15): 359-360

12 Hale FA, Sylvestre AM, Miller C. The use of a prosthetic appliance to manage a large palatal defect in a dog. J Vet Dent 1997;14(02): 61-64

13 Bryant KJ, Moore K, McAnulty JF. Angularis oris axial pattern buccal flap for reconstruction of recurrent fistulae of the palate. Vet Surg 2003;32(02):113-119

14 Dupoirieux L, Plane L, Gard C, Penneau M. Anatomical basis and results of the facial artery musculomucosal flap for oral reconstruction. Br J Oral Maxillofac Surg 1999;37(01):25-28

15 Evans HE, ed. Miller's Anatomy of the Dog. 4th ed. Philadelphia: Saunders; 2013

16 Lanz OI. Free tissue transfer of the rectus abdominis myoperitoneal flap for oral reconstruction in a dog. J Vet Dent 2001;18(04): 187-192

17 Remedios AM, Bauer MS, Bowen CV. Thoracodorsal and caudal superficial epigastric axial pattern skin flaps in cats. Vet Surg 1989;18(05):380-385

18 Spodnick GJ, Hudson LC, Clark GN, Pavletic MM. Use of a caudal auricular axial pattern flap in cats. J Am Vet Med Assoc 1996;208 (10):1679-1682

19 Anderson DM, Charlesworth TC, White RAS. A novel axial pattern skin flap based on the lateral thoracic artery in the dog. Vet Comp Orthop Traumatol 2004;17:73-77 